\title{
NANO-FLUID EFFECTS ON TOTAL ENTROPY GENERATION THROUGH PLATE HEAT EXCHANGERS
}

\author{
M. Samy Hefny, A. Taher Hussein, A. Mostafa Hamed, N. A. Mahmoud \\ Department of Mechanical power Engineering, Ain Shams University, Faculty of \\ Engineering, Cairo, Egypt. \\ Nomenclature \\ A Total surface area $\left(\mathrm{m}^{2}\right)$ \\ $\mathrm{c}_{\mathrm{p}} \quad$ Specific heat capacity $(\mathrm{J} / \mathrm{kg} \mathrm{K})$ \\ $\mathrm{D}_{\mathrm{p}}$ Port diameter $(\mathrm{mm})$ \\ $\mathrm{H}$ Depth of corrugation (mm) \\ $\mathrm{k}_{\mathrm{w}}$ Thermal conductivity of plate material (W/m K) \\ min Mass flow rate $(\mathrm{Kg} / \mathrm{sec})$ \\ $\mathrm{N}_{\mathrm{c}} \quad$ Number of channels for cold or hot streams \\ S Entropy (W/K) \\ t Plate thickness (mm) \\ $\mathrm{L}_{\mathrm{h}} \quad$ Horizontal distance between center of ports $(\mathrm{mm})$ \\ $\mathrm{T}$ Temperature $\left({ }^{0} \mathrm{C}\right)$ \\ $\mathrm{L}_{\mathrm{v}} \quad$ Vertical distance between center of ports (mm) \\ W Plate width inside gasket $(\mathrm{mm})$ \\ V゙ Volume flow rate (LPM)
}

\section{Greek Letters}

$\begin{array}{rlll}\beta \quad \text { Chevron angle }\left(^{0}\right) & & \Delta & \text { Change } \\ \beta \quad \text { Density }\left(\mathrm{kg} / \mathrm{m}^{3}\right) & & \\ \text { Subscript } & & \\ \mathrm{c} \text { cold } & \mathrm{i} & \text { inlet } \\ \text { gen generation } & \mathrm{nf} & \text { Nano-fluid } \\ \mathrm{h} \text { hot } & \mathrm{o} & \text { outlet }\end{array}$

Abbreviations

CSP Concentrated Solar Power

HTC Heat Transfer Coefficient

HTF Heat Transfer Fluid

MWCNT Multi-Walled Carbon Nano-Tubes

DI De-Ionized

LPM Liter Per Minute

\begin{abstract}
A comparative study and results analysis performed for evaluating the entropy generation through corrugated plate heat exchanger by using Nano particles of MWCNT dispersed in DI water, using three different concentrations of MWCNT of $0.25 \mathrm{~g} / \mathrm{liter}, 0.5 \mathrm{~g} / \mathrm{liter}$ and $1 \mathrm{~g} / \mathrm{liter}$. Besides, the variation of the hot Nano-DI water inlet temperature at $\mathrm{T}_{\mathrm{h}, \mathrm{i}}=50^{\circ} \mathrm{C}, 60^{\circ} \mathrm{C}, 70^{\circ} \mathrm{C}$ and $80^{\circ} \mathrm{C}$; by varying the volume flow rate of the hot Nano-DI water side at $\mathrm{V}_{\mathrm{h}}=1 \mathrm{LPM}, 2$ LPM, $3 \mathrm{LPM}$, 4LPM and $5 \mathrm{LPM}$, and varying volume flow rate of the cold water side at $\mathrm{V}_{\mathrm{c}}=$ 1 LPM, 2 LPM, 3 LPM, 4LPM and 5 LPM. The total entropy generation "S $S_{\text {gen }}$ increases with the increase of the volume flow rate of the hot fluid side. Moreover, the total entropy generation increases by increasing the inlet temperature of the hot fluid side. Moreover, the total entropy generation decreases with decreasing the volume flow rates of the cold fluid side. Also, the total entropy generation increases by increasing the Nano particles concentration in the DI water, except for the $0.5 \mathrm{~g} / \mathrm{liter}$, it shows lower values for the total
\end{abstract}


entropy generation. However, the 1 g/liter Nano-DI water reaches $155 \%$ increase over the DI water, at $80^{\circ} \mathrm{C}$.

\section{INTRODUCTION:}

A lot of applications involve continuous processes of heating and cooling, such as: power generation, refrigeration and air conditioning, microelectronics, heat pipes, etc. Considering the rapid increase in energy demand, decreasing energy loss due to ineffective use, has become an important task in present time. Moreover, a reduction in energy consumption is possible by enhancing the performance of such systems that involve heat which has major effect on carbon footprints as well. There is a real desire to enhance the efficiency of heat transfer through the heat exchangers, which will lead to reduction of the sizes of such equipment and accordingly, the associated costs of production, operation and power consumption. This can be achieved in many ways, such as: modifying fluid properties, surface shape, roughness, attaching objects to increase surface area and turbulences (Wen et al., 2009). The most frequently used working fluids or coolants through the heat exchangers are: water, ethylene glycol, engine oil, refrigerants. However, the heat transfer ability is limited by the working fluid transport properties. One of the methods for heat transfer enhancement is the application of additives to the working fluids to change the fluid transport properties and flow features. One of the most important parameters in the heat transfer process, to achieve energy efficient heat exchanger, is the thermal conductivity " $k$ " of the working fluid, which is relatively low when compared to the thermal conductivity of solids, in general, which have much higher thermal conductivities than fluids. Due to the giant improvements in Nanotechnology, it becomes possible to produce solid particles within the nanometer sizes $(<100 \mathrm{~nm})$. Hence, an innovative idea of dispersing Nano particles into base fluids was proposed, to produce liquid suspensions, which are called "Nanofluids", to use them in heat transfer enhancement of working fluids, as they can improve the effective thermal conductivity of working fluids, which was proposed first by Masuda et al. 1993 and Choi et al. 1995. Therefore, the potential benefits of Nano fluids could provide intensive performance, size/weight, and cost advantages. From here came the idea to disperse nanoparticles into DI water to enhance its thermal conductivity behavior to improve the convective heat transfer through heat exchangers. The type of base fluid used in this research is "De-Ionized Water", as it is used in capturing solar energy in solar collectors' applications. So, the main objective of the current study is, to show the effect of nanofluids on entropy generation, experimentally in heat exchangers, causing the reduction in area of heat transfer needed and pumping power. (Huang et al, 2016) studied the effect of using hybrid nanofluid mixture, as a hot fluid, of $1.89 \%$ volume fraction of $\mathrm{Al}_{2} \mathrm{O}_{3} /$ water and $0.0111 \%$ volume fraction of MWCNT/water, mixed at volume ratio of 2.5:1, experimentally on pressure drop and heat transfer properties in a plate heat exchanger with chevron corrugations. The hybrid nanofluid had slightly higher heat transfer coefficient than that of $\mathrm{Al}_{2} \mathrm{O}_{3}$ /water nanofluid and water, at the same flow velocity, due to the small added amount of MWCNT, and the pressure drop of hybrid nanofluid was smaller than that of $\mathrm{Al}_{2} \mathrm{O}_{3}$ /water nanofluid, and slightly higher than that of water. (Safi et al, 2014) examined experimentally the convective heat transfer properties of $\mathrm{MWCNT}-\mathrm{TiO}_{2}$ /water hybrid nanofluid, as hot stream, flowed through plate heat exchanger at various concentrations (from 0.02 to $0.08 \mathrm{wt}$. \%) and temperatures (from 36 to $60{ }^{\circ} \mathrm{C}$ ) and volume flow rates of hot fluid from (2 to $\left.3.5 \mathrm{LPM}\right)$. Results showed that the heat transfer coefficient increased with increasing the mass fraction and volume flow rate of nanofluid, and with decreasing the inlet temperature of hot nanofluid. (Kabeel et al, 2013) examined experimentally the laminar convective heat transfer coefficient, heat transfer rate, pressure drop and effectiveness of $\mathrm{Al}_{2} \mathrm{O}_{3}$ /water nanofluid, as hot stream, flowed through corrugated plate heat exchanger at various volume concentrations (from 1 to $4 \%$ ). Results showed that effectiveness decreased. The heat transfer coefficient increased with increasing nanoparticles volume fraction and Reynolds number of nanofluid, and reached $13 \%$ enhancement, at $4 \%$ volume fraction, at constant Reynolds number, with $9.8 \%$ uncertainty. Moreover, pressure drop increased by $45 \%$, and pumping power rose by $95 \%$ over the base fluid, at $4 \%$ volume fraction. They were doubt about results of nanofluids in their research and concluded that $2 \%$ volume fraction would be optimum considering heat transfer enhancement with respect to pumping power rise. 
- Methodology:

In the present research, it is targeted to investigate experimentally the entropy generation of hot stream of MWCNT / DI water, at mass concentrations of $0.25 \mathrm{~g} / \mathrm{liter}, 0.5 \mathrm{~g} / \mathrm{liter}$ and 1 g/liter, and at various inlet temperatures of $50{ }^{\circ} \mathrm{C}, 60{ }^{\circ} \mathrm{C}, 70{ }^{\circ} \mathrm{C}$ and $80{ }^{\circ} \mathrm{C}$, through counter flow arrangement in corrugated plate heat exchanger, for evaluating the performance of using Nano particles of MWCNT dispersed in DI water, by varying the volume flow rate of the hot Nano-DI water side at $\mathrm{V}_{\mathrm{h}}=1 \mathrm{LPM}, 2 \mathrm{LPM}, 3 \mathrm{LPM}, 4 \mathrm{LPM}$ and $5 \mathrm{LPM}$, and varying volume flow rate of the cold water side at $\mathrm{V}_{\mathrm{c}}=1 \mathrm{LPM}, 2 \mathrm{LPM}, 3$ LPM, 4LPM and 5 LPM.

\section{- Nano-DI water preparation:}

In the current research, DI water is used as the base fluid, in which nanoparticles are dispersed. Moreover, MWCNTs purchased from (Nanotech Egypt Inc., Egypt) with $10 \mathrm{~nm}$ diameter and $100 \mathrm{~nm}$ length, are used as the nanoparticles.

MWCNT/ DI water is prepared using Ultrasonicator, (Hielscher, Ultrasound technology Inc., Germany) existed in (Excellence Center of Science \& Technology, Egypt), to prepare mass concentrations of $0.25 \mathrm{~g} /$ liter, $0.5 \mathrm{~g} /$ liter and $1 \mathrm{~g} /$ liter by dispersing the required mass of MWCNT, into the available mass of DI water. Figures (1, a and b) show preparation of MWCNT/ DI water using Ultrasonicator and the TEM photo of MWCNT/ DI water, prepared Nano-fluid.

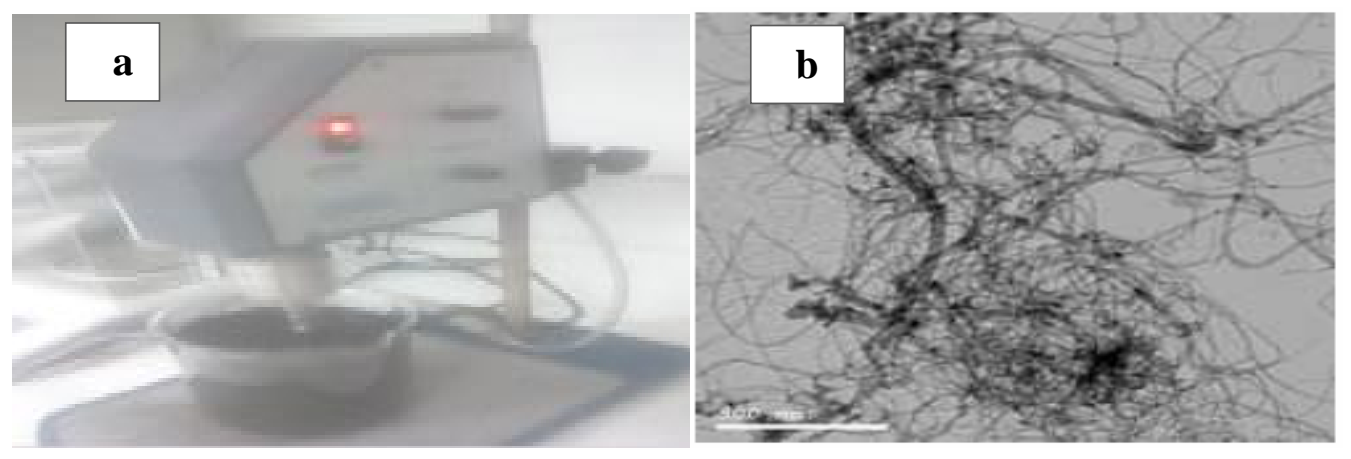

Figure (1, a and b): preparation of MWCNT/ DI water using Ultrasonicator and the TEM photo of MWCNT/ DI water.

\section{- Nano-DI water thermo-physical properties:}

The specific heat capacity " $\mathrm{c}_{\mathrm{p}, \mathrm{nf}}$ " is measured by differential scanning calorimetry technique (DSC Q2000, TA instruments Inc., England). Moreover, the density " $\rho_{\mathrm{nf}}$ " is measured by weighing the mass of known volume of the prepared Nano-DI water. Table (1) shows the measured thermo-physical properties of MWCNT/ DI water at various mass concentrations and temperatures.

Table (1): Thermo-physical properties for MWCNT/ DI water.

\begin{tabular}{|c|c|c|c|c|}
\hline $\begin{array}{l}\text { Nano- } \\
\text { DI water }\end{array}$ & $\begin{array}{c}\text { Mass } \\
\text { concentratio } \\
\text { n (g/liter) }\end{array}$ & $\begin{array}{c}\mathbf{T} \\
\left({ }^{\circ} \mathbf{C}\right)\end{array}$ & $\underset{(\mathbf{k g} / \mathbf{m} 3)}{\rho_{\mathrm{nf}}}$ & $\begin{array}{c}\text { cp, }{ }_{\text {,ff }} \\
(\mathrm{J} / \mathrm{kg} \mathrm{K})\end{array}$ \\
\hline \multirow{11}{*}{ 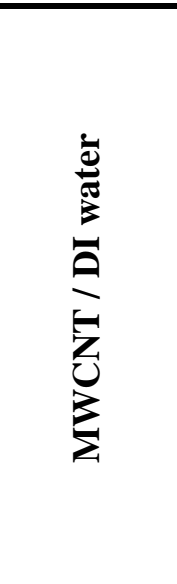 } & \multirow{4}{*}{1} & 50 & 1049.976 & 6439.5 \\
\hline & & 60 & 1047.091 & 7295.38 \\
\hline & & 70 & 1045.168 & 8346.53 \\
\hline & & 80 & 1042.283 & 10027.5 \\
\hline & \multirow{4}{*}{0.5} & 50 & 1018.994 & 5815.09 \\
\hline & & 60 & 1016.051 & 6654.3 \\
\hline & & 70 & 1014.090 & 7644.48 \\
\hline & & 80 & 1011.147 & 8649.7 \\
\hline & \multirow[t]{3}{*}{0.25} & 50 & 1003.498 & 5502.89 \\
\hline & & 60 & 1000.527 & 6333.76 \\
\hline & & 70 & 998.546 & 7293.45 \\
\hline
\end{tabular}


\begin{tabular}{ll}
\hline Plate width inside gasket, $\mathrm{W}(\mathrm{mm})$ & 100
\end{tabular}

Vertical distance between center of ports, $\mathrm{L}_{\mathrm{v}}(\mathrm{mm}) \quad 357$

Horizontal distance between center of ports, $\mathrm{L}_{\mathrm{h}}(\mathrm{mm}) \quad 60$

Port diameter, $\mathrm{D}_{\mathrm{p}}(\mathrm{mm}) \quad 30$

Number of plates

Depth of corrugation, $\mathrm{H}(\mathrm{mm}) \quad 1.2$

$\begin{array}{lr}\text { Total surface area, A }\left(\mathrm{m}^{2}\right) & 0.222\end{array}$

Plate thickness, $\mathrm{t}(\mathrm{mm}) \quad 0.5$

Number of channels for cold or hot streams, $\mathrm{N}_{\mathrm{c}}$

Chevron angle, $\beta \quad 60^{\circ}$

Thermal conductivity of plate material, $\mathrm{k}_{\mathrm{w}}(\mathrm{W} / \mathrm{m} \mathrm{K}) \quad 16.5$

\begin{tabular}{|l|l|l|l|l|l}
\hline & & $\mathbf{8 0}$ & $\mathbf{9 9 5 . 5 7 5}$ & $\mathbf{7 8 3 7 . 0 4}$ & \multirow{2}{*}{} \\
\cline { 1 - 2 } & &
\end{tabular}

\section{- Test rig and procedure:}

Corrugated plate heat exchanger, (Model: M3-FG, Alfa Laval Inc., Sweden) is used, with chevron angle of $60{ }^{\circ} \mathrm{C}$, to give the best heat transfer performance (Focke et. al, 1985), with plate interior dimensional and geometrical details as shown in figure (2) and table (2).

Table (2): Internal dimensional and geometrical details for the (M3-FG) Alfa Laval plate heat exchanger.

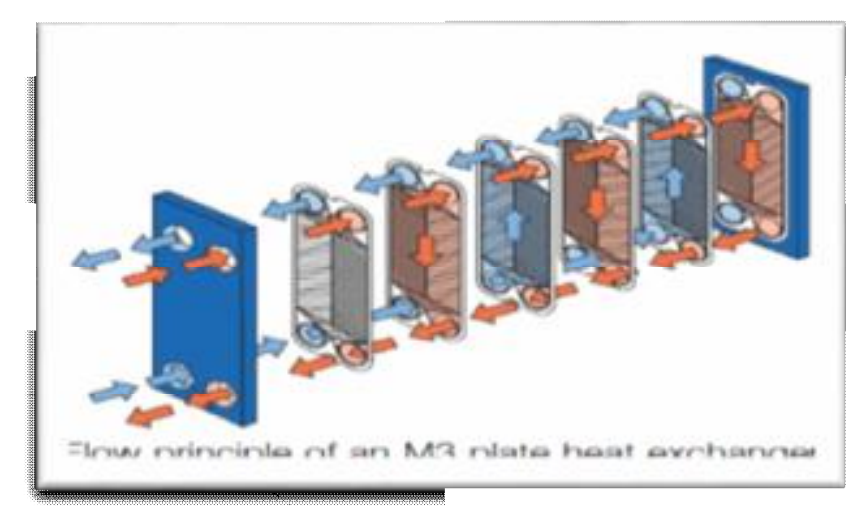

Figure (2): overview of the heat exchanger

The experimental test rig mainly composed of two flow loops. First one for the hot fluid stream and the second for the cold fluid stream. Both streams enter the plate heat exchanger in counter flow arrangement to exchange heat between each other, as shown from line diagram, in figure (3). 


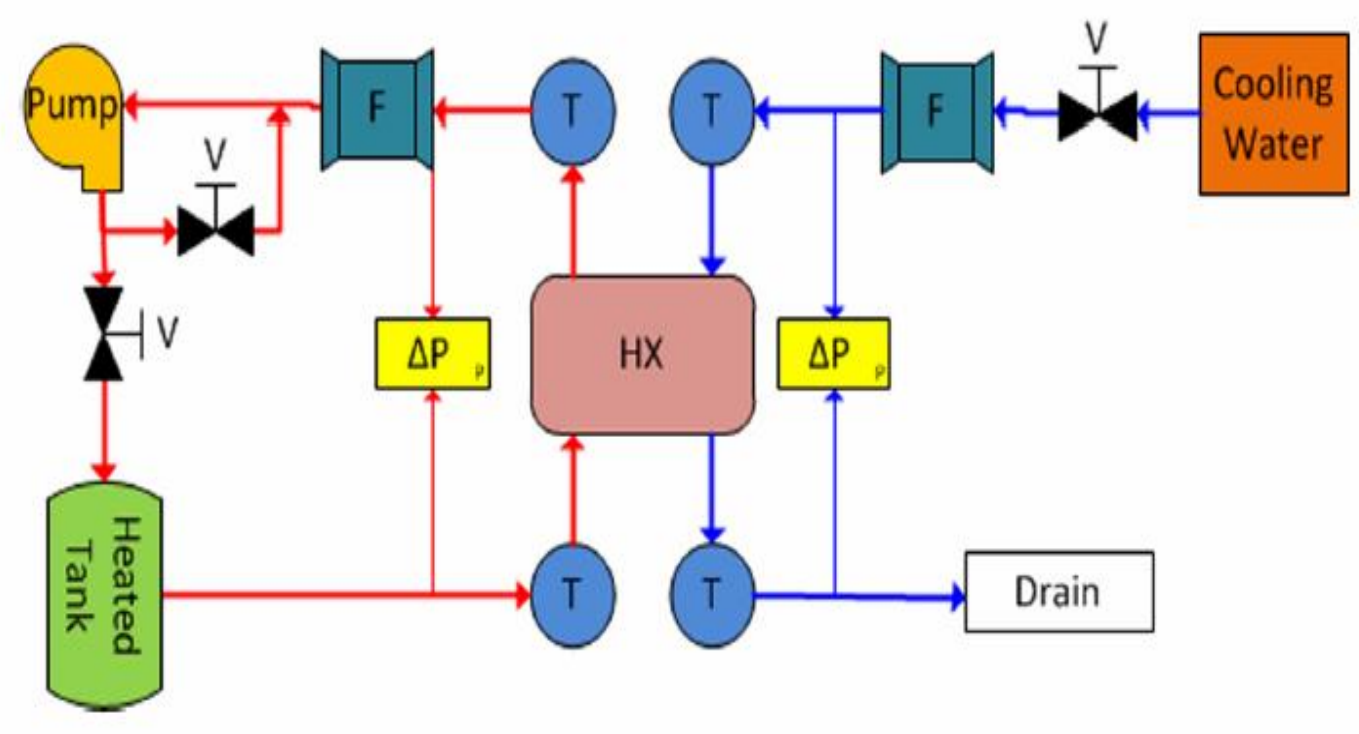

Figure (3): Line diagram for the experimental test setup

The hot fluid stream is the Nano-DI water loop and the cold fluid stream is the tap water loop. The Nano-DI water is stored in 5 liters stainless steel tank, with four, $2.5 \mathrm{KW}$ each, immersed electric heaters, to heat the Nano-DI water. The desired inlet temperature of the hot Nano-DI water to the heat exchanger is controlled by a digital thermostat and by using Variac of 2.5 $\mathrm{kw}$. The Nano-DI water is drawn by a gear pump and pumped through the plate heat exchanger, on the hot stream side of it, and then, back to the tank. The volume flow rate of the hot Nano-DI water is measured at the hot stream outlet port of the heat exchanger, using visual indication rotameter.

The cold water is stored in 10 liters plastic tank. . The inlet temperature of the cold water to the heat exchanger varies between $25^{\circ} \mathrm{C}$ and $30{ }^{\circ} \mathrm{C}$, as it comes from the main grid. The cold water is drawn by a centrifugal pump and pumped through the plate heat exchanger on the cold stream side of it, and then, back to the drain. The volume flow rate of the cold water is measured at the cold stream inlet port of the heat exchanger, using visual indication rotameter. The inlet and outlet temperatures from the heat exchanger for the hot and cold streams are measured immediately at the entrance and exit ports of the heat exchanger, using four water-proof temperature sensors.

\section{- Test procedure:}

For the selected mass concentration of the Nano-DI water sample either to be $0.25 \mathrm{~g} / \mathrm{liter}, 0.5$ $\mathrm{g} /$ liter or $1 \mathrm{~g} / \mathrm{liter}$. The desired inlet temperature of the hot Nano-DI water to the heat exchanger inlet port $\mathrm{S} 1$ is preset, using the digital thermostat and Variac, at $50{ }^{0} \mathrm{C}, 60{ }^{0} \mathrm{C}, 70$ ${ }^{0} \mathrm{C}$ and $80^{\circ} \mathrm{C}$, for each separate test run. While the inlet temperature of the cold water to the inlet port S3, comes from city water, changes between $25{ }^{0} \mathrm{C}$ and $30{ }^{0} \mathrm{C}$ during all test runs. Then the volume flow rate of the hot Nano-DI water stream is varied, using Inverter, at 1, 2, 3, 4 and 5 LPM, for each separate test run. While varying the volume flow rate of the cold water stream, using valve, at 1,2,3,4 and 5 LPM, for the selected volume flow rate of the hot stream. Upon reaching steady state equilibrium conditions, the outlet temperatures, of the hot Nano-DI water are measured using the water-proof temperature sensors.

\section{- Thermodynamics and heat transfer analysis:}

The mass flow rates of the Nano-DI water and the cold water through heat exchanger can be calculated from Eq.(1) and Eq.(2), respectively.

$$
\begin{aligned}
\dot{\mathrm{m}}_{\mathrm{nf}} & =\rho_{\mathrm{nf}} \cdot \mathrm{V}_{\mathrm{n}} \\
\dot{\mathrm{m}}_{\mathrm{s}} & =\rho_{\mathrm{c}} \cdot \dot{\mathrm{V}}_{\mathrm{a}}
\end{aligned}
$$

The entropy change for the hot stream of Nano-DI water and the cold water through heat exchanger paths can be obtained from Eq.(3) and Eq.(4), respectively. 


$$
\begin{aligned}
& \Delta S_{n f}=\dot{m}_{n f} \cdot\left(s_{n f o}-s_{n f i}\right)=m_{n f} \cdot c_{p n f} \cdot \ln \left(\frac{T_{n f o}}{T_{n f, i}}\right)
\end{aligned}
$$

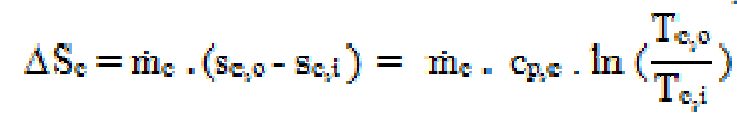

Hence, the total entropy generation for the heat exchanger can be calculated from Eq.(5).

$$
\dot{\mathrm{S}}_{\mathrm{gen}}=\Delta \mathrm{S}_{\mathrm{nf}}+\Delta \mathrm{S}_{\mathrm{s}}
$$

Figure (4) shows the thermal entropy profile for the hot and cold streams in a counter flow corrugated plate heat exchanger.

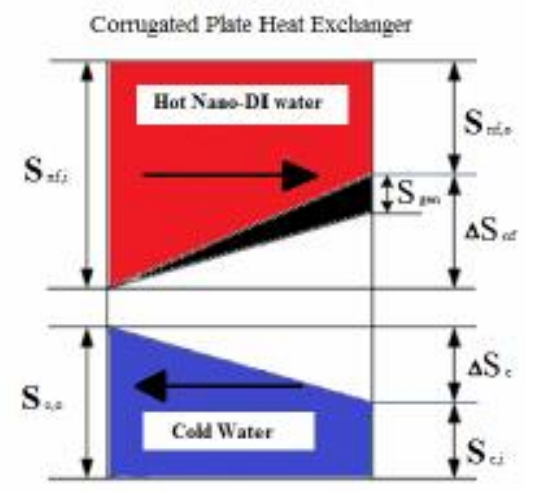

Figure (4): Entropy thermal profile for counter flow plate heat exchanger.

Total entropy generation " $S_{\text {gen }}$ " results and analysis:

Figure (5) shows the variation of the total entropy generation through the heat exchanger for

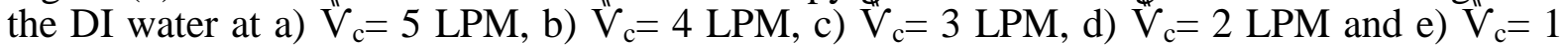
LPM, it is noticed that the total entropy generation increases, with the increase of the volume flow rate of the hot fluid side. Moreover, the total entropy generation increases, by increasing the inlet temperature of the hot fluid side. Moreover, the total entropy generation decreases with decreasing the volume flow rates of the cold fluid side. The same behavior was observed for the three different concentrations of $0.25 \mathrm{~g} / \mathrm{liter}, 0.5 \mathrm{~g} / \mathrm{liter}$ and $1 \mathrm{~g} / \mathrm{liter}$ of Nano-DI water in Figures (6), (7) and (8) respectively. Moreover, the total entropy generation increases, by increasing the Nano particles concentration in the DI water, except for the $0.5 \mathrm{~g} / \mathrm{liter}$, it shows lower values for the total entropy generation. Figures (9), (10), (11) and (12) show the variation of the total entropy generation at constant inlet temperatures of $\mathrm{T}_{\mathrm{h}, \mathrm{i}}=50^{\circ} \mathrm{C}, 60^{\circ} \mathrm{C}$, $70^{\circ} \mathrm{C}$ and $80^{\circ} \mathrm{C}$ respectively. The $0.25 \mathrm{~g} /$ liter sample showed increase in the total entropy generation at $50^{\circ} \mathrm{C}$, over the $0.5 \mathrm{~g} /$ liter, but lower than the $1 \mathrm{~g} /$ liter sample. Moreover, the increase in total entropy generation increases, with increasing temperature of hot Nano-DI water from $60^{\circ} \mathrm{C}$ to $80^{\circ} \mathrm{C}$, reaching $118 \%$ increase over the DI water, at $80^{\circ} \mathrm{C}$. Moreover, the increase in total entropy generation decreases, by decreasing the volume flow rate of the cold fluid, at the same hot Nano-DI water inlet temperature. The $0.5 \mathrm{~g} / \mathrm{liter}$ sample showed decrease in the total entropy generation at $50^{\circ} \mathrm{C}$, below the DI water, $0.25 \mathrm{~g} /$ liter and $1 \mathrm{~g} / \mathrm{liter}$ samples. Moreover, the total entropy generation decreases, with decreasing flow rate of the cold water side. However, the total entropy generation increases, with increasing temperature of hot Nano-DI water from $60^{\circ} \mathrm{C}$ to $80^{\circ} \mathrm{C}$, reaching $82 \%$ increase over the DI water, at $80^{\circ} \mathrm{C}$. However, still lower than the $0.25 \mathrm{~g} / \mathrm{liter}$ and $1 \mathrm{~g} / \mathrm{liter}$ samples. The $1 \mathrm{~g} / \mathrm{liter}$ sample showed the highest increase in the total entropy generation at $50^{\circ} \mathrm{C}$, over the DI water, $0.25 \mathrm{~g} /$ liter and $0.5 \mathrm{~g} /$ liter samples. Moreover, the total entropy generation increases, with increasing temperature of hot Nano-DI water from $60^{\circ} \mathrm{C}$ to $80^{\circ} \mathrm{C}$, reaching $155 \%$ increase over the DI water, at $80^{\circ} \mathrm{C}$. Moreover, the increase in the total entropy generation decreases, by decreasing volume flow rate of the cold fluid, at the same hot Nano-DI water inlet temperature. The increase of the total entropy generation of the heat exchanger with increasing inlet temperature of the hot Nano-DI water, may be due to the increase of the specific heat property of Nano-DI water with increasing temperature, and due to the increase of external source of irreversibility due to the rise in the temperature difference between the hot and cold sides in the heat exchanger. 
1) DI water results:

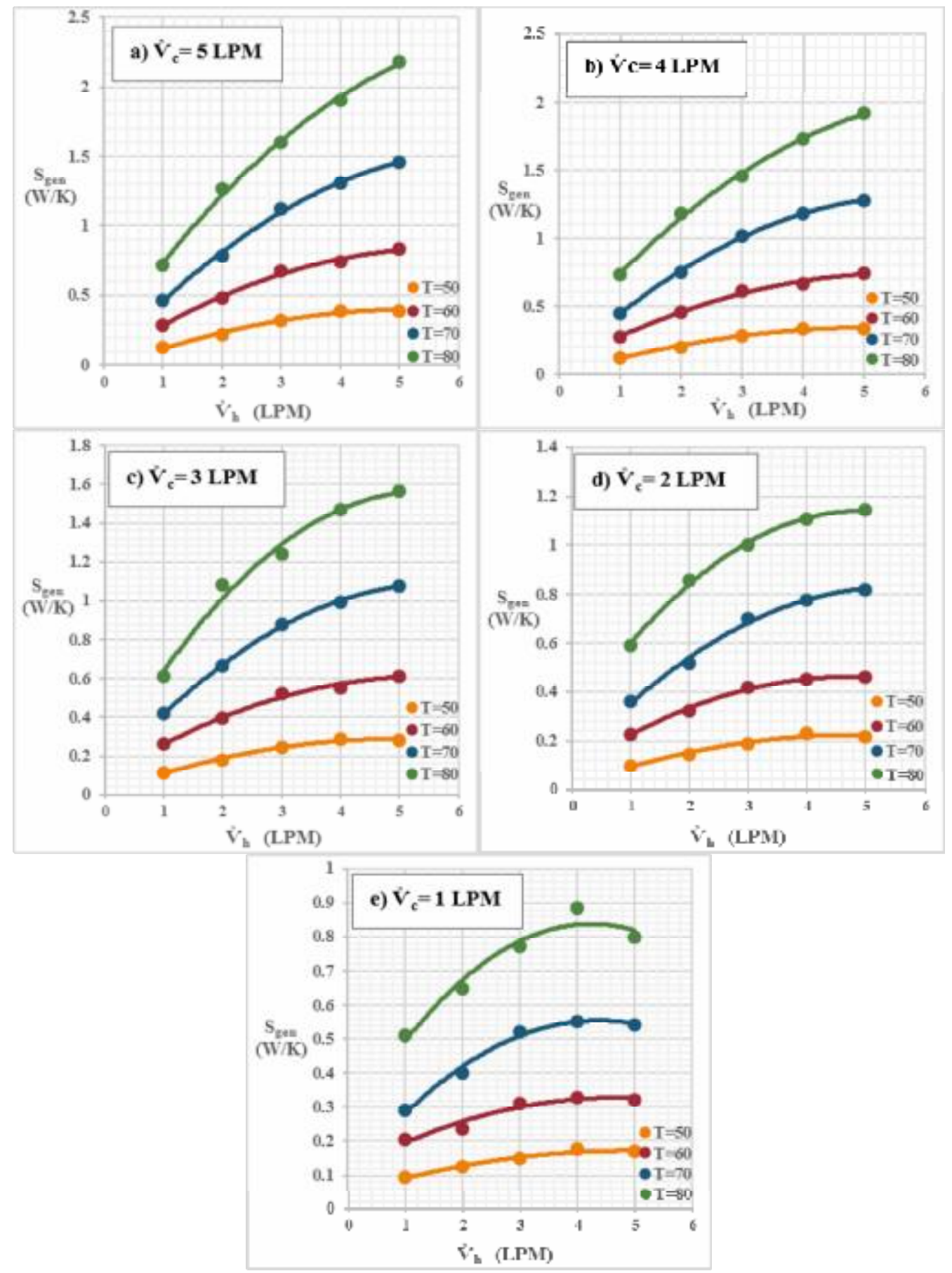

Figure (5): Variation of Sgen with volume flow rate of DI water at a) $\breve{V} c=5$ LPM, b) $\breve{V} c=4$ LPM, c) 3 LPM, d) V゙c= 2 LPM and e) V゙c= 1 LPM. 
2) Nano-DI water, 0.25 g/liter results:

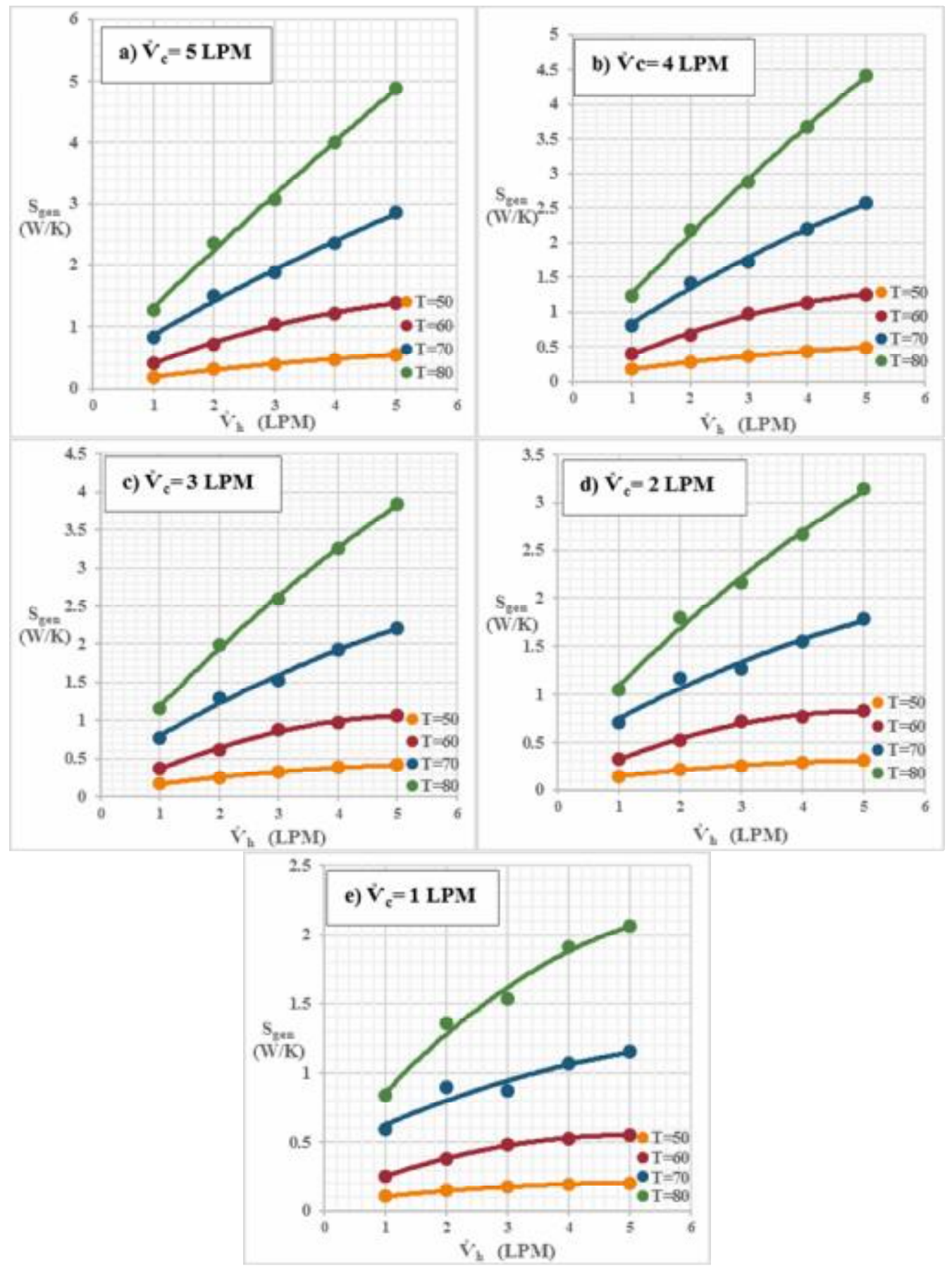

Figure (6): Variation of Sgen with volume flow rate of Nano-DI water, $0.25 \mathrm{~g} / \mathrm{liter}$, at a) $\mathrm{V}(\mathrm{c}=5 \mathrm{LPM}, \mathrm{b}$ )

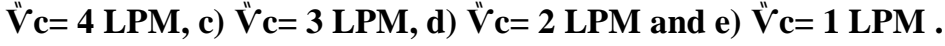




\section{3) Nano-DI water, $0.5 \mathrm{~g} /$ liter results:}
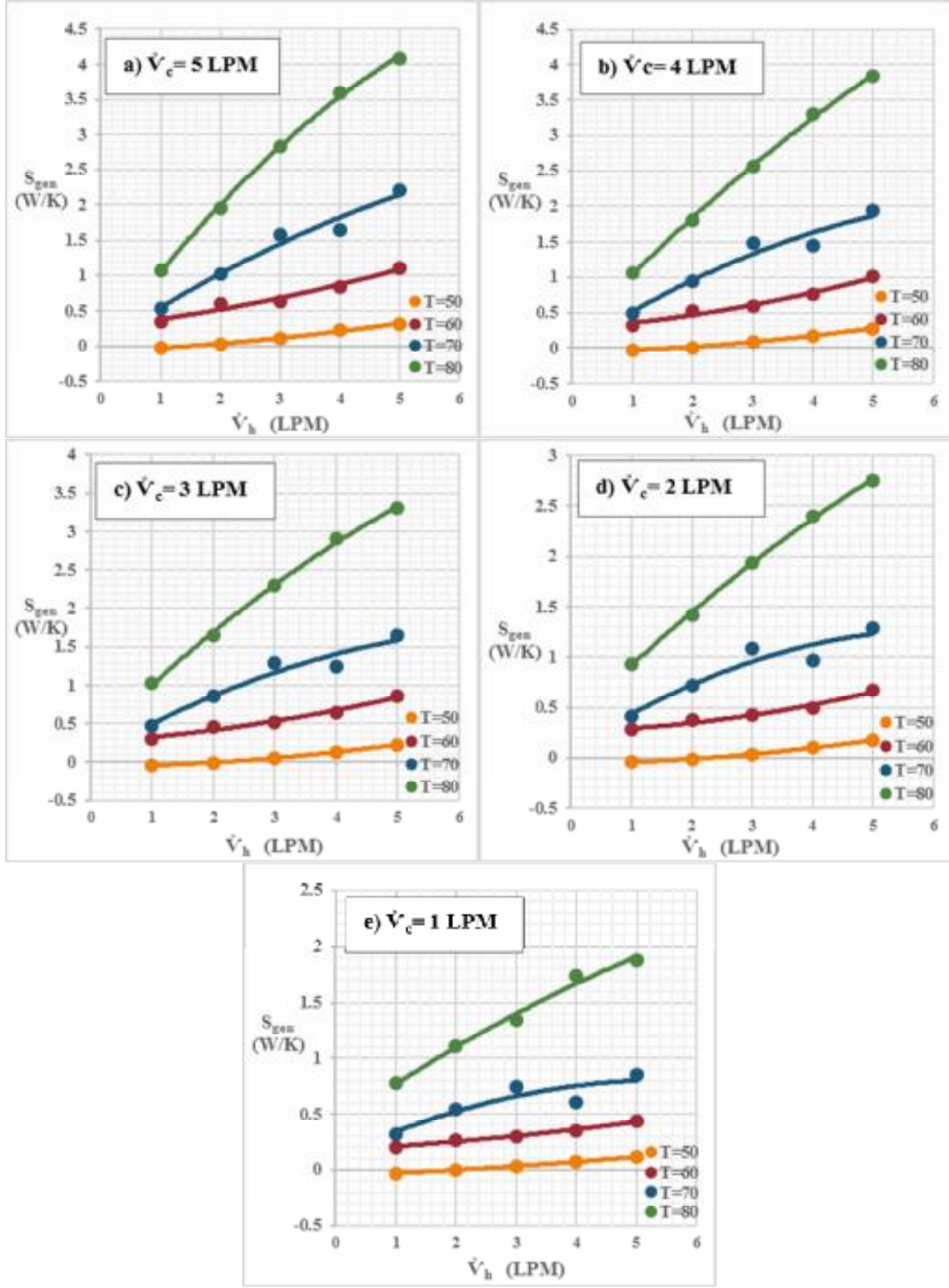

Figure (7): Variation of Sgen with volume flow rate of Nano-DI water, $0.5 \mathrm{~g} /$ liter, at a) V゙c= 5 LPM, b) V゙ $c=4$ LPM, c) V゙c= 3 LPM, d) V゙c= 2 LPM and e) V゙c= 1 LPM . 


\section{4) Nano-DI water, 1 g/liter results:}
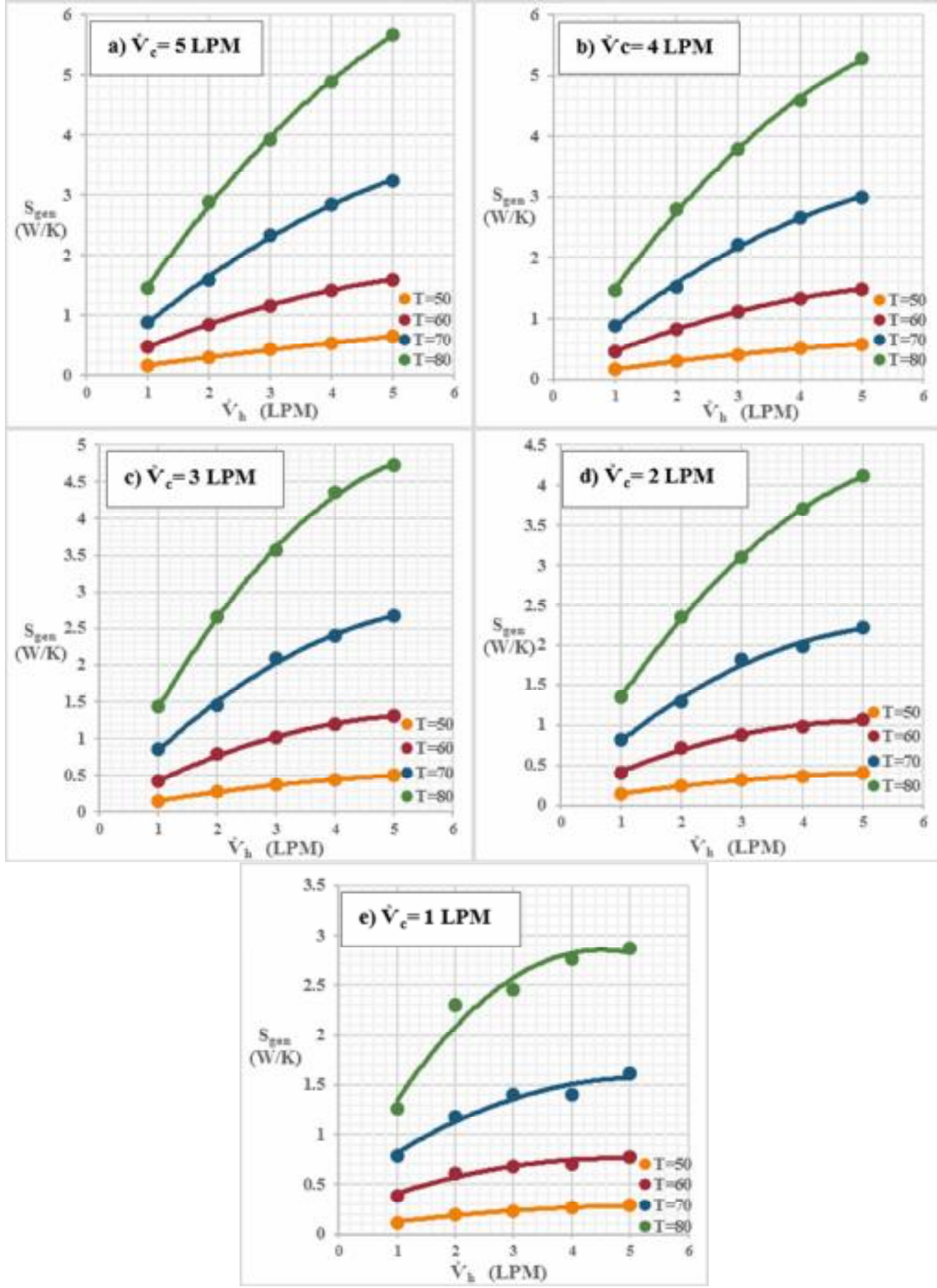

Figure (8): Variation of Sgen with volume flow rate of Nano-DI water, $1 \mathrm{~g} / \mathrm{liter}$, at a) $゙$ c $=5$ LPM, b) 
5) $S_{\text {gen }}$ at $T_{h, i}=50{ }^{\circ} \mathrm{C}$ results:

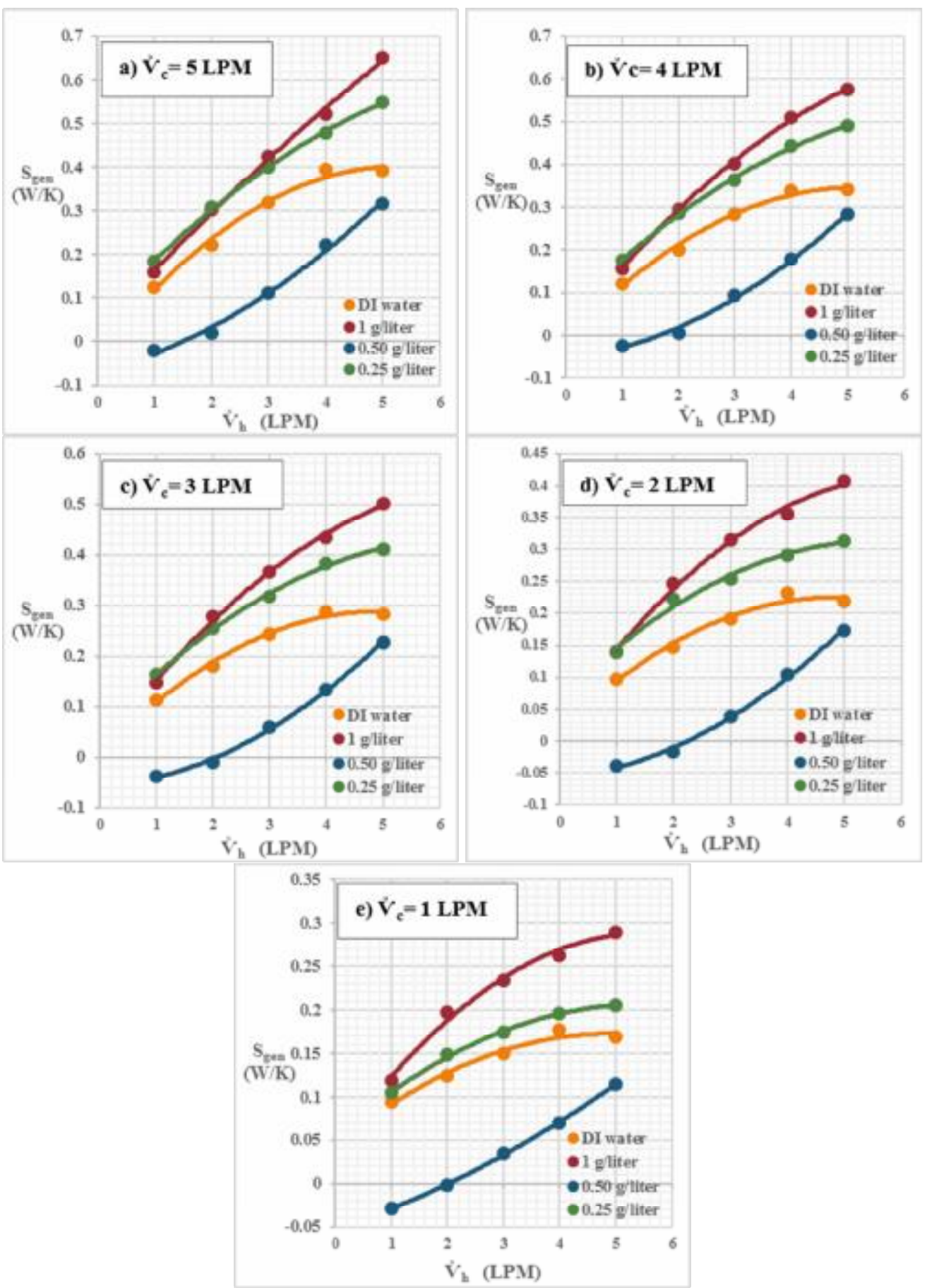

Figure (9): Variation of Sgen with volume flow rate of Nano-DI water, at Th,i=50 0C, at a) $\mathrm{V} c=5 \mathrm{LPM}, \mathrm{b}$ ) $\ddot{V} c=4$ LPM, c) $\ddot{V} c=3$ LPM, d) V゙ $c=2$ LPM and e) 
6) $S_{\text {gen }}$ at $T_{h, i}=60^{\circ} \mathrm{C}$ results:

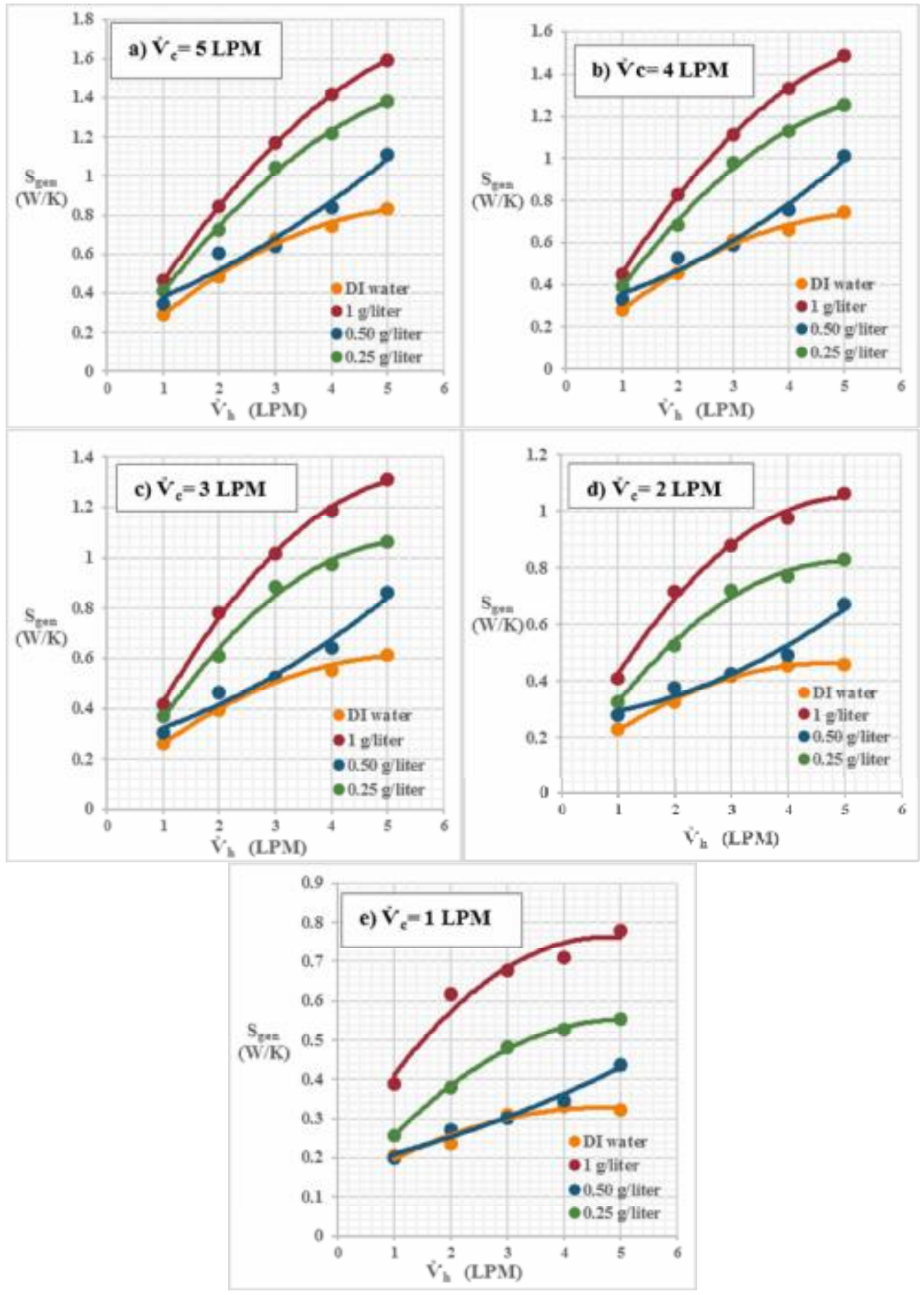

Figure (10): Variation of Sgen with volume flow rate of Nano-DI water, at Th,i=60 0C, at a) $\mathrm{V} \mathrm{c}=5 \mathrm{LPM}$,

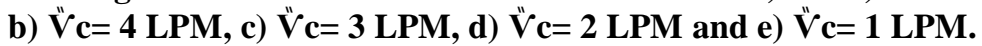


7) $S_{\text {gen }}$ at $T_{h, i}=\mathbf{7 0}^{\circ} \mathrm{C}$ results:
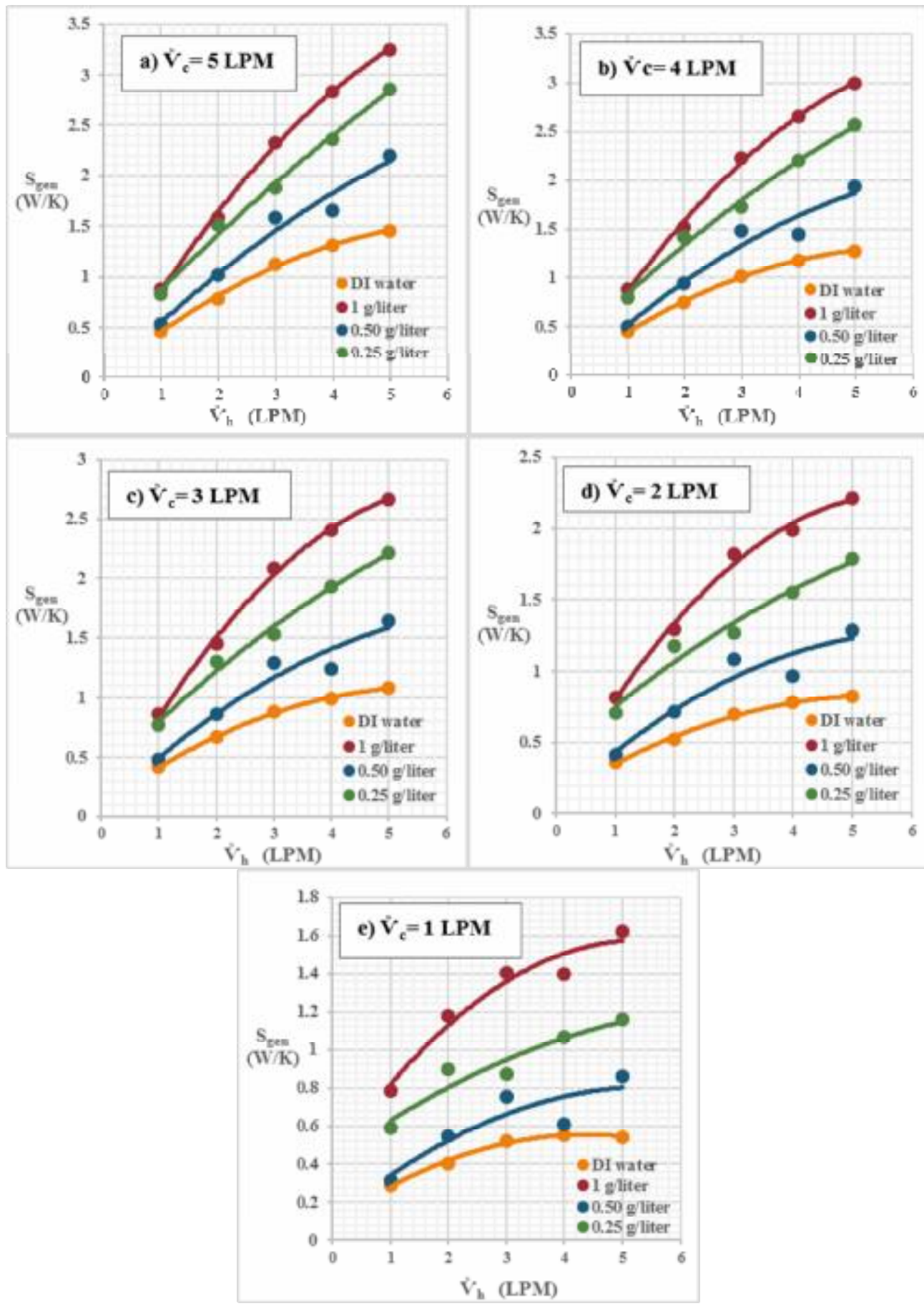

Figure (11): Variation of Sgen with volume flow rate of Nano-DI water, at $\mathrm{Th}, \mathrm{i}=\mathbf{7 0} 0 \mathrm{C}$, at a) $\mathrm{V} \mathrm{c}=5 \mathrm{LPM}$, b) V゙c= 4 LPM, c) V゙ $(c=3$ LPM, d) V゙ $c=2$ LPM and e) V゙c= 1 LPM. 
8) $S_{\text {gen }}$ at $T_{h, i}=80^{\circ} \mathrm{C}$ results:

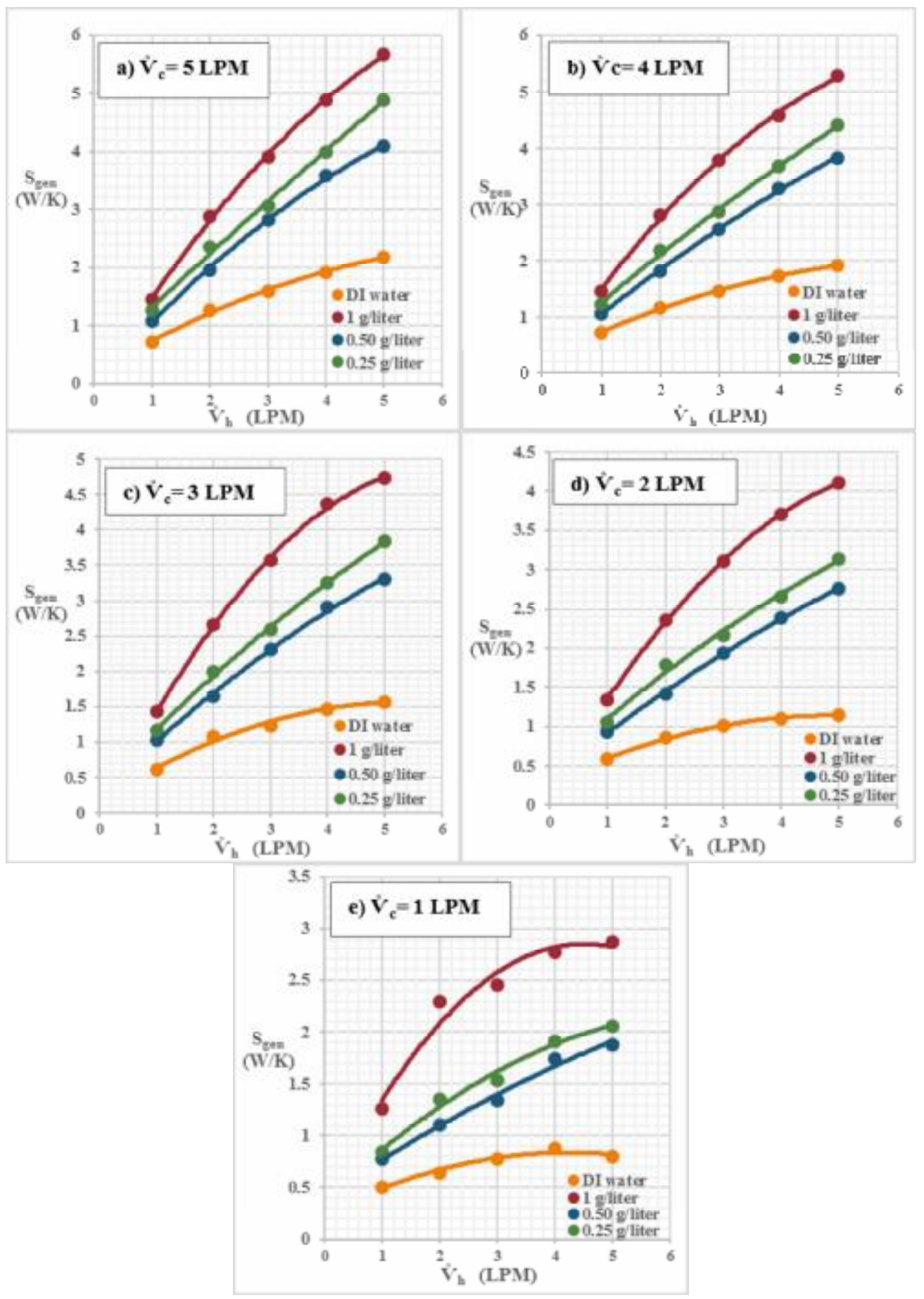


Figure (12): Variation of Sgen with volume flow rate of Nano-DI water, at Th,i=80 0C, at a) $\mathrm{V} c=5 \mathrm{LPM}$, b) V゙c= 4 LPM, c) V゙c= 3 LPM, d) V゙ $c=2$ LPM and e) V゙c= 1 LPM.

\section{CONCLUSION:}

The total entropy generation " $S_{\text {gen }}$ " increases, with the increase of the volume flow rate of the hot fluid side. Moreover, the total entropy generation increases, by increasing the inlet temperature of the hot fluid side. Moreover, the total entropy generation decreases with decreasing the volume flow rates of the cold fluid side. Moreover, the total entropy generation increases, by increasing the Nano particles concentration in the DI water, except for the $0.5 \mathrm{~g} / \mathrm{liter}$, it shows lower values for the total entropy generation. Moreover, the 1 $\mathrm{g} /$ liter Nano-DI water reaches $155 \%$ increase over the DI water, at $80^{\circ} \mathrm{C}$.

\section{REFERENCES}

1. Wen, D., Lin, G., Vafaei, S., and Zhang, K. (2009). Review of nanofluids for heat transfer applications. Particuology, 7(2), 141-150.

2. Choi, S. U. S. (1995). Enhancing thermal conductivity of fluids with nanoparticles. ASME-Publications-Fed, 231, 99-106.

3. Huang, D., Wu, Z., and Sunden, B. (2016). Effects of hybrid nanofluid mixture in plate heat exchangers. Experimental Thermal and Fluid Science, 72, 190-196.

4. Safi, M. A., Ghozatloo, A., Hamidi, A. A., and Shariaty-Niassar, M. (2014). Calculation of Heat Transfer Coefficient of MWCNT-TiO2 Nanofluid in Plate Heat Exchanger. International Journal of Nanoscience and Nanotechnology, 10(3), 153162.

5. Kabeel, A. E., El Maaty, T. A., and El Samadony, Y. (2013). The effect of using nano-particles on corrugated plate heat exchanger performance, Applied Thermal Engineering, 52(1), 221-229.

6. Ray, D. R., Das, D. K., and Vajjha, R. S. (2014). Experimental and numerical investigations of nanofluids performance in a compact minichannel plate heat exchanger. International Journal of Heat and Mass Transfer, 71, 732-746.

7. Fard, H., Talaie, M. R., and Nasr, S. (2011). Numerical and experimental investigation of heat transfer of zno/water nanofluid in the concentric tube and plate heat exchangers. Thermal Science, 15(1), 183-194.

8. Focke, W. W., Zachariades, J., \& Olivier, I. (1985). The effect of the corrugation inclination angle on the thermohydraulic performance of plate heat exchangers. International Journal of Heat and Mass Transfer, 28(8), 1469-1479.

9. Godson, L., Raja, B., Lal, D. M., \& Wongwises, S. (2010). Enhancement of heat transfer using nanofluids - an overview. Renewable and sustainable energy reviews, 14(2), 629-641

10. Lenert, A., \& Wang, E. N. (2012). Optimization of nanofluid volumetric receivers for solar thermal energy conversion. Solar Energy, 86(1), 253-265.

11. Hordy, N., Rabilloud, D., Meunier, J. L., \& Coulombe, S. (2014). High temperature and long-term stability of carbon nanotube nanofluids for direct absorption solar thermal collectors. Solar Energy, 105, 82-90. 